Check for updates

Cite this: RSC Adv., 2017, 7, 50838

Received 22nd September 2017 Accepted 17th October 2017

DOI: 10.1039/c7ra10507j

rsc.li/rsc-advances

\section{C-C coupling reactions using a gold(III) phosphorus complex confined within metal-organic framework fibers in aqueous solution}

\author{
Seyed Mohsen Sadeghzadeh, (D) *ab Rahele Zhiani, ${ }^{\text {ab }}$ Shokufe Emrani ${ }^{\mathrm{ab}}$ \\ and Mahdieh Ghabdian ${ }^{\mathrm{ab}}$
}

Novel fibrous nano-silica (KCC-1) was functionalized with chlorodiphenylphosphine with phosphinefunctionalized nanoparticle groups acting as strong performers, so that gold(II) could form complexes without aggregation on the fibers of $\mathrm{KCC}-1 / \mathrm{PPh}_{2}$ microspheres (KCC-1/PPh $/ \mathrm{Au}$ ). Compared to the traditional mesoporous silica materials, KCC-1 remarkably enhances the accessibility of gold(III) due to its three dimensional hierarchical channel structure. HPG@KCC-1/PPh $/ \mathrm{Au}$ NPs were used for the first time as a catalyst for the $\mathrm{C}-\mathrm{C}$ cross-coupling between allylarenes or methyl acrylate and benzoxazole, and they showed excellent catalytic activities under green conditions.

\section{Introduction}

Metal complexes have high catalytic activities, and they have been a topic of research due to these properties. ${ }^{1-5}$ Among the reported metals used in catalysis, gold is the most stable catalyst, and it has been widely studied because of its catalytic properties, which can be leveraged for various uses, such as in the Sonogashira, ${ }^{6-8}$ Suzuki-Miyaura, ${ }^{9-11}$ Heck $^{\mathbf{1 2 - 1 4}}$ and Hiyama ${ }^{15-17}$ reactions, in the Larock heteroannulation reaction, ${ }^{18-21}$ for the degradation of pollutants, ${ }^{22}$ for hydrogenation $^{23}$ and in fuel cells. ${ }^{24}$ In recent years, it has been proven that the use of complex functional groups, either grafted or smeared onto solid supports, plays an important role in preventing the aggregation of metal catalysts. ${ }^{25-27}$

In view of developing new solid supported catalysts, metal complexes with a support of choice provide a large field for the discovery of new, highly active nanocatalysts for important and challenging reactions, which also offer the additional advantage of recyclability. ${ }^{28-30}$ Mesoporous silica nanoparticles (MSNs) such as SBA-15, MCM-41 and HMS are widely applied as ideal supports for heterogeneous catalysts due to their high surface area, tunable pore size and excellent stability. However, the poor accessibility of the active sites inside the pores, resulting from the mass transfer of reactants or clogging of the pores, may limit the application of these materials in some reactions. ${ }^{31,32} \mathrm{KCC}-1$ has a high surface area, but more importantly, this high surface area is due to fibres

${ }^{a}$ Department of Chemistry, Faculty of Sciences, Neyshabur Branch, Islamic Azad University, Neyshabur, Iran.E-mail: seyedmohsen.sadeghzadeh@gmail.com

${ }^{b}$ Young Researchers and Elite Club, Neyshabur Branch, Islamic Azad University, Neyshabur, Iran and not pores, which makes this material one-of-a-kind. ${ }^{33}$ Additionally, the 3D architectures generated by the hierarchical pore structure with macropores can also improve the mass transfer of the reactant. ${ }^{34,35}$ This would be an ideal catalyst support for making noble metal-based catalysts that provide a high availability of active sites and excellent catalytic activity.

The $\mathrm{C}-\mathrm{C}$ cross-coupling reaction between aryl halides and organoboranes is one of the most efficient methods for the synthesis of biaryls, which have significant applications in the synthesis of biologically active materials..$^{36-38}$ Herein, we report the synthesis of KCC-1, which was functionalized with glycidol to form HPG@KCC-1, which was then phosphinefunctionalized to form the ordered mesofiber organosilica material (HPG@KCC-1/PPh ${ }_{2}$ using chlorodiphenylphosphine. The HPG@KCC-1/PPh $\mathrm{P}_{2}$ material was then used as an efficient support for the immobilization of gold(III) (HPG@KCC-1/PPh $/ \mathrm{Au}$ ) and applied for different $\mathrm{C}-\mathrm{C}$ cross-coupling reactions. We are pleased to report crosscoupling reactions between allylarenes or methyl acrylate and benzoxazole (Scheme 1).

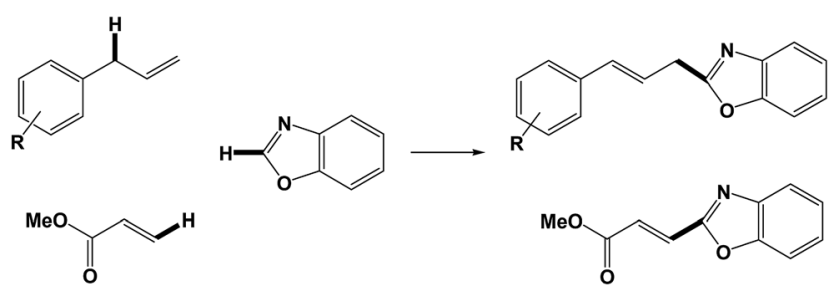

Scheme 1 Arylation of benzoxazole with simple allylarenes or methyl acrylate in the presence of HPGQKCC-1/PPh $/$ /Au NPs. 


\section{Experimental}

\section{Materials and methods}

Chemical materials were purchased from Fluka and Merck in high purity. Melting points were determined in open capillaries using an Electrothermal 9100 apparatus and are uncorrected. The particle size and morphology were investigated by SEM using a FESEM-TESCAN MIRA3. The chemical composition of the catalyst on the surface of the MOF was determined by X-ray photoelectron spectroscopy (XPS) using a Kratos Axis Ultra DLD spectrometer with $\mathrm{Al} \mathrm{K} \alpha$ as the source. Thermogravimetric analysis (TGA) was carried out on a NETZSCH STA449F3 at a heating rate of $10{ }^{\circ} \mathrm{C} \mathrm{min}^{-1}$ under nitrogen. ${ }^{1} \mathrm{H}$ and ${ }^{13} \mathrm{C} \mathrm{NMR}$ spectra were recorded on a BRUKER DRX-300 AVANCE spectrometer at 300.13 and $75.46 \mathrm{MHz}$, and a BRUKER DRX-400 AVANCE spectrometer at 400.22 and $100.63 \mathrm{MHz}$, respectively. Elemental analyses for $\mathrm{C}, \mathrm{H}$ and $\mathrm{N}$ were performed using a Heraeus CHN-O-Rapid analyzer. Purity determination of the products and reaction monitoring were accomplished by TLC on silica gel polygram SILG/UV 254 plates. Mass spectra were recorded on a Shimadzu GCMS-QP5050 mass spectrometer.

\section{General procedure for the preparation of KCC-1}

The KCC-1 NP core-shell microspheres were synthesized according to the previously reported method..$^{39}$ TEOS $(2.5 \mathrm{~g})$ was dissolved in a solution of cyclohexane $(30 \mathrm{~mL})$ and 1-pentanol $(1.5 \mathrm{~mL})$. A stirred solution of cetylpyridinium bromide (CPB, $1 \mathrm{~g})$ and urea $(0.6 \mathrm{~g})$ in water $(30 \mathrm{~mL})$ was then added. The resulting mixture was continually stirred for $45 \mathrm{~min}$ at room temperature then placed in a Teflon-sealed hydrothermal reactor and heated at $120{ }^{\circ} \mathrm{C}$ for $5 \mathrm{~h}$. The silica formed was isolated by centrifugation, washed with deionized water and acetone, and dried in a drying oven. This material was then calcined at $550{ }^{\circ} \mathrm{C}$ for $5 \mathrm{~h}$ in air.

\section{General procedure for the preparation of HPG@KCC-1 NPs}

$2 \mathrm{mmol}$ of KCC-1 NPs was dispersed in a mixture of $80 \mathrm{~mL}$ of toluene and $1.0 \mathrm{mmol}$ of potassium methylate $\left(\mathrm{CH}_{3} \mathrm{OK}\right)$, followed by the addition of $10 \mathrm{~mL}$ of anhydrous dioxane. $2.0 \mathrm{~g}$ of glycidol was added dropwise over a period of $1 \mathrm{~h}$. After vigorous stirring for $2 \mathrm{~h}$, the final suspension was repeatedly washed, filtered several times and dried at $60{ }^{\circ} \mathrm{C}$ in air. ${ }^{39}$

\section{General procedure for the preparation of HPG@KCC-1/PPh} NPs

HPG@KCC-1 (0.6 g) was suspended in $60 \mathrm{~mL}$ of a $0.1 \mathrm{M}$ toluene solution of $\mathrm{ClPPh}_{2}$ and the colloidal solution was refluxed for 48 h. The HPG@KCC-1/PPh ${ }_{2}$ NPs were isolated and purified by repeated washing (firstly in ethanol and then in deionized water) and centrifugation. ${ }^{40}$

\section{General procedure for the preparation of $\mathrm{HPG} @ \mathrm{KCC}-1 / \mathrm{PPh}_{2} /$ Au NPs}

HPG@KCC-1/PPh $/$ Au nanoparticles were prepared by a simple method from our previous work. ${ }^{40}$ Sodium tetrachloroaurate
(III) hydrate (5 mmol) was dispersed in dry $\mathrm{CH}_{2} \mathrm{Cl}_{2}(20 \mathrm{~mL})$ and HPG@KCC-1/ $\mathrm{PPh}_{2}$ (0.1 g) nanoparticles were added. The mixture was then heated to $60{ }^{\circ} \mathrm{C}$ for $12 \mathrm{~h}$ under a nitrogen atmosphere. The resulting solid was separated by centrifugation and washed 3 times with $\mathrm{CH}_{2} \mathrm{Cl}_{2}$, ethanol and $\mathrm{H}_{2} \mathrm{O}$. After drying at room temperature under vacuum, HPG@KCC-1/PPh $/$ $\mathrm{Au}$ NPs were obtained as a powder.

\section{General procedure for the arylation of benzoxazole}

A mixture of benzoxazole $(1 \mathrm{mmol})$, allylarenes or methyl acrylate (1 mmol), $\mathrm{K}_{2} \mathrm{CO}_{3}(1 \mathrm{mmol})$ and HPG@KCC- $1 / \mathrm{PPh}_{2} / \mathrm{Au} \mathrm{NPs}$ $(1 \mathrm{mg})$ was stirred with heating under reflux in TFA $(3 \mathrm{~mL})$ for 2 hours. $\mathrm{K}_{2} \mathrm{~S}_{2} \mathrm{O}_{8}(1 \mathrm{mmol})$ was then added consecutively. The mixture was stirred at room temperature for 10 min under an $\mathrm{N}_{2}$ atmosphere, then heated under reflux for 6-8 h. The catalyst was separated by filtration. Evaporation of the solvent of the filtrate under reduced pressure gave the crude products. The pure products were isolated by chromatography on silica gel eluted with petroleum ether : EtOAc $(3: 1)$.

\section{Results and discussion}

The synthesis of the HPG@KCC-1/PPh $/ \mathrm{Au}$ NPs involved several steps. The fibers of KCC-1 have many $\mathrm{Si}-\mathrm{OH}$ groups on their surfaces, and thus it was expected that KCC-1 could be easily functionalized with chlorodiphenylphosphine, followed by the ring opening polymerization of glycidol to form HPG@KCC-1/ $\mathrm{PPh}_{2}$. Furthermore, the phosphine groups on HPG@KCC-1/ $\mathrm{PPh}_{2}$ could support gold(III) complexes (Scheme 2).

We examined the effect of the solvent for the arylation of benzoxazole with allylarene using HPG@KCC-1/PPh $/$ Au NPs at room temperature (Table 1 ). The solvent does affect the catalyst performance. $n$-Hexane, dioxane, $\mathrm{CCl}_{4}$ and cyclohexane (nonpolar solvents) did not give any amount of the desired product (Table 1, entry 11-14). $i$-PrOH, ethanol, methanol and $\mathrm{H}_{2} \mathrm{O}$ (protic polar solvents) gave the product in lower yields. $\mathrm{CH}_{3} \mathrm{CN}$, THF, $\mathrm{CH}_{2} \mathrm{Cl}_{2}$, DMF, toluene, dioxane, $\mathrm{CHCl}_{3}$, EtOAc and DMSO (aprotic solvents) also gave the product in lower yields. In this study, it was found that conventional heating in

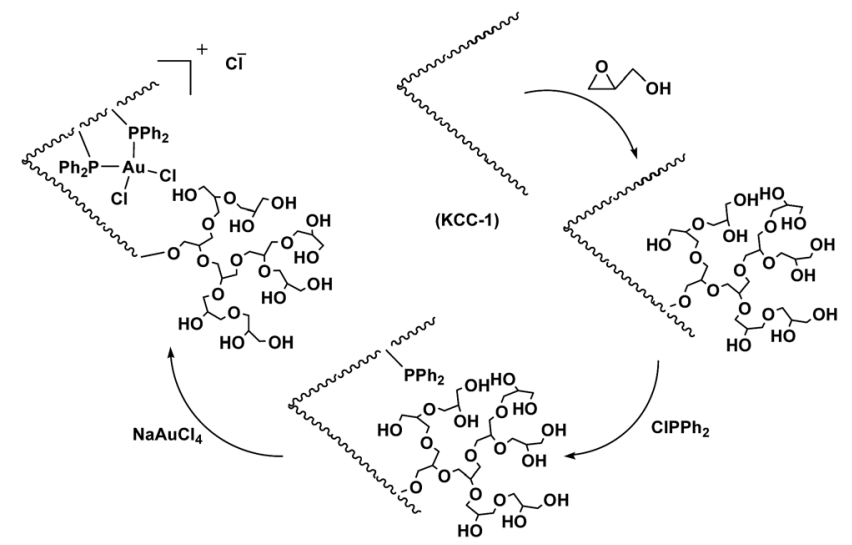

Scheme 2 Schematic illustration of the synthesis of HPGaKCC-1/ $\mathrm{PPh}_{2} / \mathrm{Au}$ NPs. 
Table 1 The effect of solvent and temperature on the reaction of benzoxazole with allylarene

\begin{tabular}{|c|c|c|c|}
\hline Entry & Solvent & Temp. $\left({ }^{\circ} \mathbf{C}\right)$ & Yield $^{a}(\%)$ \\
\hline 1 & Solvent-free & 100 & - \\
\hline 2 & TFA & Reflux & 87 \\
\hline 3 & EtOH & Reflux & 29 \\
\hline 4 & $i$-PrOH & Reflux & 23 \\
\hline 5 & $\mathrm{MeOH}$ & Reflux & 26 \\
\hline 6 & $\mathrm{CH}_{3} \mathrm{CN}$ & Reflux & 11 \\
\hline 7 & $\mathrm{CH}_{2} \mathrm{Cl}_{2}$ & Reflux & 18 \\
\hline 8 & EtOAc & Reflux & 15 \\
\hline 9 & $\mathrm{CHCl}_{3}$ & Reflux & 22 \\
\hline 10 & DMSO & Reflux & 21 \\
\hline 11 & Dioxane & Reflux & - \\
\hline 12 & Cyclohexane & Reflux & - \\
\hline 13 & $n$-Hexane & Reflux & - \\
\hline 14 & $\mathrm{CCl}_{4}$ & Reflux & - \\
\hline
\end{tabular}

TFA was more efficient than using organic solvents. We also studied the decisive role of temperature in the arylation of benzoxazole in the presence of HPG@KCC-1/PPh $/ \mathrm{Au}$ NPs as a catalyst. The best temperature for this reaction was heating under reflux, which does cause changes in the efficiency of the reaction, showing that the catalytic activity is susceptible to the reaction temperature.

The activity of the described catalyst was investigated through the reaction of benzoxazole with allylarene. Initially, we examined the arylation of benzoxazole with allylarene in different bases and oxidants (Table 2). It is well known that bases play a crucial role in coupling reactions, so we attempted the reaction in the presence of various organic and inorganic bases (Table 2, entries 6-15). As a result, we found that the most-used base, $\mathrm{K}_{2} \mathrm{CO}_{3}$, was the most efficient base for these reaction conditions. Also, it was found that $\mathrm{K}_{2} \mathrm{~S}_{2} \mathrm{O}_{8}$ is the best oxidant for the reaction. The removal of $\mathrm{K}_{2} \mathrm{~S}_{2} \mathrm{O}_{8}$ from the

Table 2 Optimization of the reaction conditions for the reaction of benzoxazole with allylarene in terms of the base and oxidant

\begin{tabular}{llll}
\hline Entry & Base & Oxidant & Yield $^{a}(\%)$ \\
\hline 1 & $\mathrm{~K}_{2} \mathrm{CO}_{3}$ & - & - \\
2 & $\mathrm{~K}_{2} \mathrm{CO}_{3}$ & $\mathrm{AgOAc}$ & 34 \\
3 & $\mathrm{~K}_{2} \mathrm{CO}_{3}$ & $\mathrm{Ag}{ }_{2} \mathrm{O}$ & 61 \\
4 & $\mathrm{~K}_{2} \mathrm{CO}_{3}$ & $\mathrm{Cu}(\mathrm{OAc})_{2}$ & 49 \\
5 & $\mathrm{~K}_{2} \mathrm{CO}_{3}$ & $\left(\mathrm{NH}_{4}\right)_{2} \mathrm{~S}_{2} \mathrm{O}_{8}$ & 18 \\
6 & $\mathrm{~K}_{2} \mathrm{CO}_{3}$ & $\mathrm{~K}_{2} \mathrm{~S}_{2} \mathrm{O}_{8}$ & 87 \\
7 & - & $\mathrm{K}_{2} \mathrm{~S}_{2} \mathrm{O}_{8}$ & - \\
8 & $\mathrm{CsF}_{2}$ & $\mathrm{~K}_{2} \mathrm{~S}_{2} \mathrm{O}_{8}$ & 68 \\
9 & $\mathrm{Na}_{2} \mathrm{CO}_{3}$ & $\mathrm{~K}_{2} \mathrm{~S}_{2} \mathrm{O}_{8}$ & 54 \\
10 & $\mathrm{E}_{3} \mathrm{~N}$ & $\mathrm{~K}_{2} \mathrm{~S}_{2} \mathrm{O}_{8}$ & 41 \\
11 & $\mathrm{NaOAc}_{12}$ & $\mathrm{~K}_{2} \mathrm{~S}_{2} \mathrm{O}_{8}$ & 35 \\
12 & $\mathrm{KOH}_{13}$ & $\mathrm{~K}_{2} \mathrm{~S}_{2} \mathrm{O}_{8}$ & 29 \\
14 & $\mathrm{~K}_{3} \mathrm{PO}_{4}$ & $\mathrm{~K}_{2} \mathrm{~S}_{2} \mathrm{O}_{8}$ & 42 \\
15 & $\mathrm{Cs}_{2} \mathrm{CO}_{3}$ & $\mathrm{~K}_{2} \mathrm{~S}_{2} \mathrm{O}_{8}$ & 55 \\
& $t \mathrm{BuOK}$ & $\mathrm{K}_{2} \mathrm{~S}_{2} \mathrm{O}_{8}$ & 14
\end{tabular}

${ }^{a}$ Isolated yields.

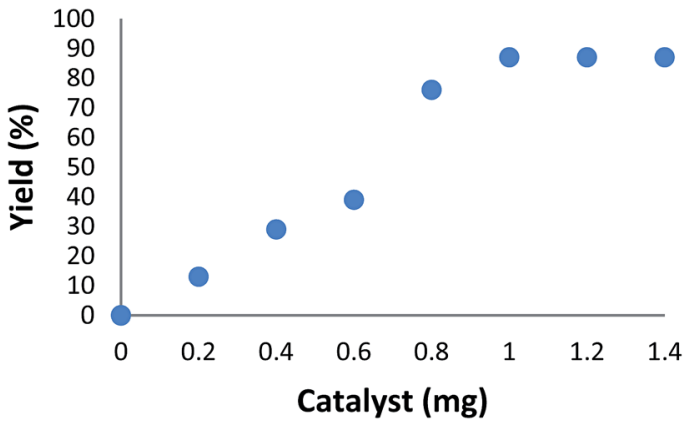

Fig. 1 The effect of increasing the amount of HPGaKCC-1/PPh $/ 2 / \mathrm{Au}$ NPs on the arylation of benzoxazole.

reaction system completely shuts down the reaction (Table 2, entry 7).

The amount of catalyst is another important factor for the arylation of benzoxazole (Fig. 1). As shown in Fig. 1, in the absence of catalyst, no product was obtained. When $0.2-0.8 \mathrm{mg}$ of catalyst was used in the model reaction, moderate yields of product were obtained. The best result was achieved when the model reaction was carried out in the presence of $1 \mathrm{mg}$ of catalyst. A rise in the catalyst amount gave no yield increase in the model reaction.

We also investigated the crucial role of time on the arylation of benzoxazole in the presence of HPG@KCC-1/PPh $/$ Au NPs as a catalyst. The results clearly indicated that the catalytic activity is sensitive to the reaction time. The best time for this reaction was $7 \mathrm{~h}$. A time of more than $7 \mathrm{~h}$ did not cause changes in the yield of the reaction (Fig. 2).

To further investigate the efficiency of the catalyst, different control experiments were performed, and the obtained information is shown in Table 3. Initially, a standard reaction was carried out using KCC-1, which showed that no amount of the desired product was formed after $10 \mathrm{~h}$ of reaction time (Table 3 , entry 1). Also, when KCC-1/PPh 2 and HPG@KCC-1/ $\mathrm{PPh}_{2}$ were used as the catalyst, a reaction was not observed (Table 3, entries 2 and 3). $\mathrm{PPh}_{2}$ or HPG could not provide the satisfactory catalytic activity under mild reaction conditions. Based on these disappointing results, we continued the studies to improve the yield of the product by adding $\mathrm{Au}(\mathrm{III})$. Notably, there was not much difference in the reaction yields when the reaction was carried out using HPG@KCC-1/PPh $/$ Au NPs and an [Au(bpy)

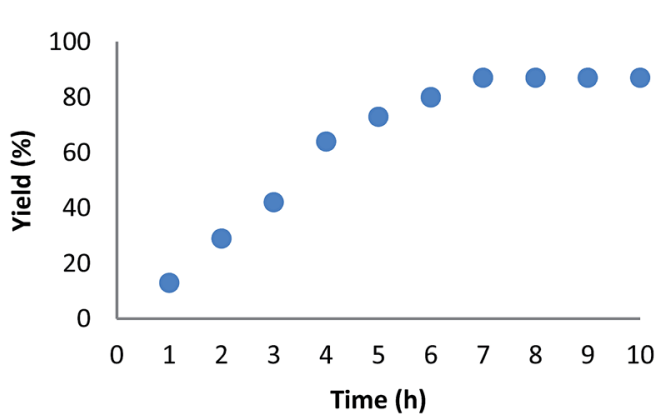

Fig. 2 The effect of time on the yield of the arylation of benzoxazole. 
Table 3 The influence of different catalysts for the arylation of benzoxazole ${ }^{a}$

\begin{tabular}{|c|c|c|c|}
\hline Entry & Catalyst & Catalyst loading & Yield $^{b}(\%)$ \\
\hline 1 & KCC-1 & $1 \mathrm{mg}$ & - \\
\hline 2 & $\mathrm{KCC}-1 / \mathrm{PPh}_{2}$ & $1 \mathrm{mg}$ & - \\
\hline 3 & HPG@KCC-1/PPh ${ }_{2}$ & $1 \mathrm{mg}$ & - \\
\hline 4 & HPG@KCC-1/PPh $/ \mathrm{Au}$ & $1 \mathrm{~mol} \%$ & 87 \\
\hline 5 & HPG@KCC-1/PPh $/ \mathrm{Au}$ & $0.8 \mathrm{~mol} \%$ & 87 \\
\hline 6 & HPG@KCC-1/PPh ${ }_{2} / \mathrm{Au}$ & $0.6 \mathrm{~mol} \%$ & 81 \\
\hline 7 & $\mathrm{HPG} @ \mathrm{SiO}_{2} / \mathrm{PPh}_{2} / \mathrm{Au}$ & $0.8 \mathrm{~mol} \%$ & 59 \\
\hline 8 & {$\left[\mathrm{Au}(\mathrm{bpy}) \mathrm{Cl}_{2}\right] \mathrm{Cl}$} & $1 \mathrm{~mol} \%$ & 88 \\
\hline
\end{tabular}

${ }^{a}$ Reaction conditions: benzoxazole $(1 \mathrm{mmol})$, allylarene $(1 \mathrm{mmol})$, HPG@KCC- $1 / \mathrm{PPh}_{2} / \mathrm{Au} \quad \mathrm{NPs} \quad\left(\begin{array}{llll}1 & \mathrm{mg}\end{array}\right), \quad \mathrm{K}_{2} \mathrm{CO}_{3} \quad\left(\begin{array}{lll}1 & \mathrm{mmol}\end{array}\right)$ and $\mathrm{K}_{2} \mathrm{~S}_{2} \mathrm{O}_{8}(1 \mathrm{mmol})$ were stirred with heating under reflux in TFA $(3 \mathrm{~mL})$ for 10 hours. ${ }^{b}$ Isolated yields.

$\left.\mathrm{Cl}_{2}\right] \mathrm{Cl}$ catalyst (Table 3, entries 4 and 8), however, $\left[\mathrm{Au}(\mathrm{bpy}) \mathrm{Cl}_{2}\right] \mathrm{Cl}$ was not recoverable or reusable for the next runs. These observations show that the reaction cycle is mainly catalyzed by $\mathrm{Au}(\mathrm{III})$ species complexed on the HPG@KCC- $1 / \mathrm{PPh}_{2}$ nanostructure. The nano-sized particles increase the exposed surface area of the active site of the catalyst, thereby enhancing the contact between the reactants and catalyst dramatically, mimicking homogeneous catalysts. As a result, HPG@KCC$1 / \mathrm{PPh}_{2} / \mathrm{Au}$ was used in the subsequent investigations because of its high reactivity, high selectivity and easy separation. The results illustrate that the amount of catalyst strongly affects the reaction progress, and the best result was obtained in the presence of $0.8 \mathrm{~mol} \%$ of catalyst (Table 3, entry 5 ). Also, the activity and selectivity of the nanocatalyst can be manipulated by tailoring the chemical and physical properties, such as the size, shape, composition and morphology. To assess the exact impact of the presence of KCC-1 in the catalyst, the HPG@KCC$1 / \mathrm{PPh}_{2} / \mathrm{Au}$ NPs were compared to $\mathrm{HPG} @ \mathrm{SiO}_{2} / \mathrm{PPh}_{2} / \mathrm{Au} \mathrm{NPs}$ (Table 3, entries 5 and 7). To check this, we looked at HPG@SiO ${ }_{2} / \mathrm{PPh}_{2} / \mathrm{Au}$ and HPG@KCC-1/PPh $/ \mathrm{Au}$ NPs, which have the same compositions but different structures. When HPG@SiO $\mathrm{SPh}_{2} / \mathrm{Au}$ was used as the catalyst, the yield of the desired product was moderate, but the yield for HPG@KCC-1/ $\mathrm{PPh}_{2} / \mathrm{Au}$ was good (Table 3, entries 5 and 7 ). The loading amount of $\mathrm{Au}(\mathrm{III})$ in the HPG@SiO${ }_{2} / \mathrm{PPh}_{2} / \mathrm{Au}$ and HPG@KCC-1/ $\mathrm{PPh}_{2} / \mathrm{Au}$ NPs was determined by inductively coupled plasma mass spectrometry (ICP-MS). The amount of $\mathrm{Au}(\mathrm{III})$ in the HPG@KCC-1/PPh $/$ /Au NPs was almost double the amount of $\mathrm{Au}$ (III) in the HPG@SiO $\mathrm{SPh}_{2} / \mathrm{Au}$ NPs (Table 4, entries 1 and 3).

Gold(III) leaching was studied by inductively coupled plasma mass spectrometry (ICP-MS) analysis of the catalyst after ten

Table 4 The loading amount of Au(III)

\begin{tabular}{|c|c|c|}
\hline Entry & Catalyst & wt $\%$ \\
\hline 1 & $\mathrm{HPG} @ \mathrm{SiO}_{2} / \mathrm{PPh}_{2} / \mathrm{Au}$ & 1.8 \\
\hline 2 & $\mathrm{KCC}-1 / \mathrm{PPh}_{2} / \mathrm{Au}$ & 3.5 \\
\hline 3 & HPG@KCC-1/PPh $2 / \mathrm{Au}$ & 3.7 \\
\hline 4 & $\mathrm{KCC}-1 / \mathrm{PPh}_{2} / \mathrm{Au}$ after ten reuses & 1.9 \\
\hline 5 & HPG@KCC-1/PPh $/$ Au after ten reuses & 3.6 \\
\hline
\end{tabular}

Table 5 Reaction of various allylarenes with benzoxazole in the presence of HPG@KCC-1/PPh $/$ /Au NPs ${ }^{a}$

Entry

${ }^{a}$ Reaction conditions: allylarenes or methyl acrylate $(1 \mathrm{mmol})$, benzoxazole $(1 \mathrm{mmol}), \mathrm{K}_{2} \mathrm{CO}_{3}(1 \mathrm{mmol}), \mathrm{K}_{2} \mathrm{~S}_{2} \mathrm{O}_{8}(1 \mathrm{mmol})$ and HPG@KCC-1/PPh $/$ Au NPs (1 mg) were stirred with heating under reflux in TFA ( $3 \mathrm{~mL}$ ) for $6-8$ hours. ${ }^{b}$ Isolated yields.

reaction cycles. The loading amount of gold(III) was found to be $3.6 \mathrm{wt} \%$, which shows negligible gold(III) leaching. These results confirm the high recyclability of the gold(III) nanocatalyst (Table 4). Also, the loading amount of gold(III) in the KCC-1/ $\mathrm{PPh}_{2} / \mathrm{Au}$ NPs was determined by ICP-MS. The amount of gold(III) in the HPG@KCC-1/PPh $/$ /Au NPs was almost equal to that in the KCC-1/ $\mathrm{PPh}_{2} / \mathrm{Au}$ NPs. However, it is interesting that this amount of gold(III) was almost the same after the catalyst was reused for ten consecutive cycles of catalysis. The amount of gold(III) in the HPG@KCC-1/PPh $/$ Au NPs was approximately double that in the

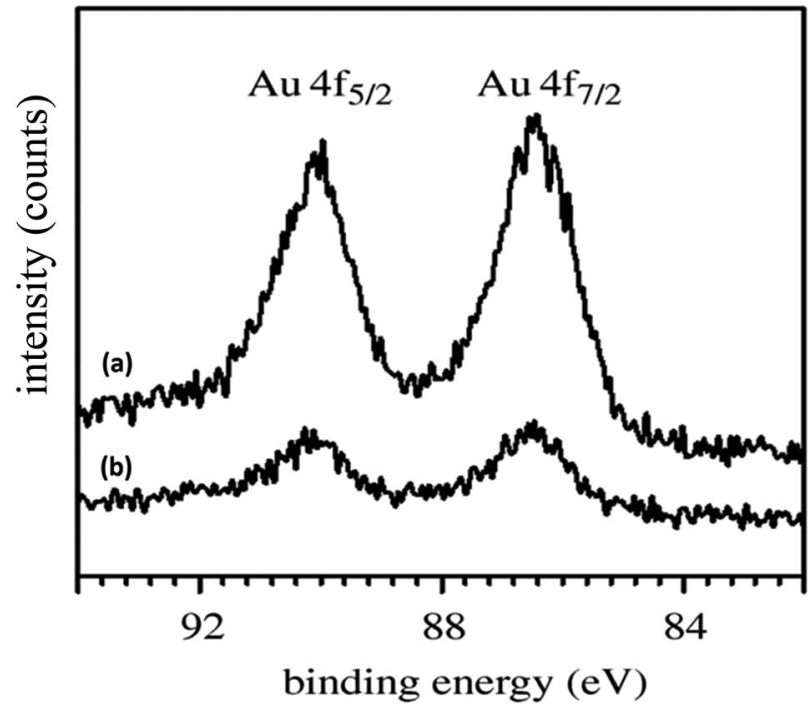

Fig. 3 XPS spectra of (a) fresh HPG@KCC-1/PPh $/$ /Au NPs and (b) HPG@KCC-1/PPh $/$ /Au NPs after ten reuses. 


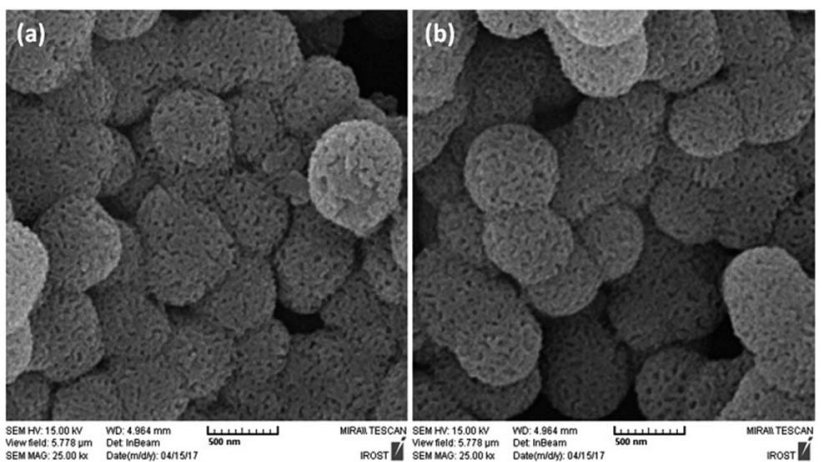

Fig. 4 SEM image of (a) fresh HPGaKCC-1/PPh $2 / A u$ NPs and (b) HPG@KCC-1/PPh $2 /$ Au NPs after ten reuses.

KCC-1/PPh $/$ Au NPs after ten reuses. This remarkable ability of the HPG@KCC-1/ $\mathrm{PPh}_{2} / \mathrm{Au}$ mesostructure may be attributed to the HPG units, which effectively manage the reaction by preventing $\mathrm{Au}$ agglomeration and releasing and recapturing gold during the reaction process (Table 4).

To examine the scope of the catalytic properties of the catalyst for the Stille coupling reaction, various types of allylarene were reacted with benzoxazole in the presence of a catalytic amount of HPG@KCC-1/PPh $/$ /Au NPs. It is noteworthy that electron-rich and electron-poor aryl halides react smoothly with phenyltributyltin under similar reaction conditions. The electron-rich allylarenes show moderate to excellent reactivity (81-87\% yield) for the formation of the corresponding products in the $\mathrm{C}-\mathrm{C}$ coupling reactions under similar reaction conditions. The relative reactivity of allylarenes towards the Au metal centre decreases in the order: $\mathrm{Me}>\mathrm{MeO}$ (Table 5, entry 2 and 4). As shown in Table 5, the $\mathrm{C}-\mathrm{C}$ coupling reaction of benzoxazole with chloroallyl arene proceeds smoothly under mild reaction conditions, giving the desired product in good yield (Table 5, entry 3). When methyl acrylate was used, the product was obtained under the same conditions (Table 5, entry 5).

To further understand the underlying reason for the significant difference in recyclability, XPS and SEM were employed to characterize the fresh and reused HPG@KCC-1/PPh $/$ /Au NPs. The XPS spectra are shown in Fig. 3. For the fresh HPG@KCC-1/

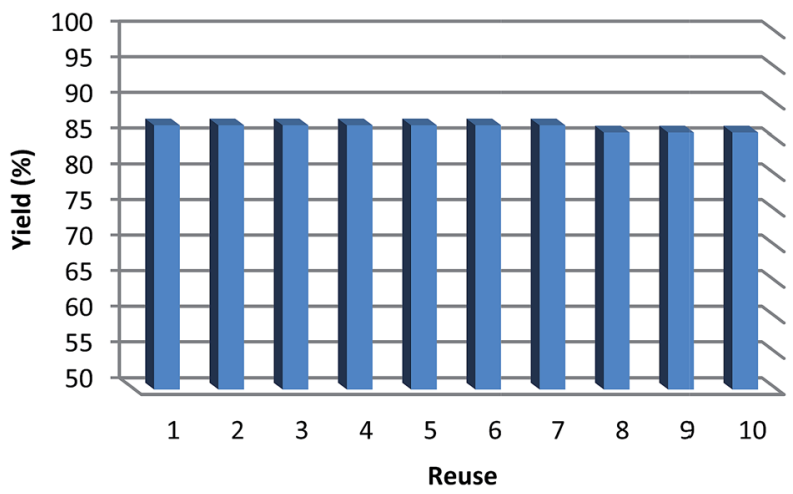

Fig. 5 The reusability of the catalyst for cross-coupling reactions between allylarenes and benzoxazole.
Table 6 The effect of HPG@KCC-1/PPh 2 complexes of metal ions on the reaction of allylarenes and benzoxazole after $10 \mathrm{~h}$

\begin{tabular}{lll}
\hline Entry & Metal ion & Yield $^{a}(\%)$ \\
\hline 1 & $\mathrm{Au}(\mathrm{III})$ & 87 \\
2 & $\mathrm{Mn}(\mathrm{II})$ & 66 \\
3 & $\mathrm{Cd}(\mathrm{II})$ & 64 \\
4 & $\mathrm{Cu}(\mathrm{II})$ & 70 \\
5 & $\mathrm{Cr}(\mathrm{III})$ & 39 \\
6 & $\mathrm{Ni}(\mathrm{II})$ & 76 \\
7 & $\mathrm{Zn}(\mathrm{II})$ & 27 \\
8 & $\mathrm{Co}(\mathrm{II})$ & 51 \\
9 & $\mathrm{Hg}(\mathrm{II})$ & 43
\end{tabular}

${ }^{a}$ Yields refer to the isolated pure product.

$\mathrm{PPh}_{2} / \mathrm{Au}$ NPs, the $\mathrm{Au} 4 \mathrm{f}_{5 / 2}$ and $\mathrm{Au} 4 \mathrm{f}_{7 / 2}$ binding energies were determined to be 89.4 and $85.7 \mathrm{eV}$, respectively. After the catalyst was reused ten times, the $89.4 \mathrm{eV}\left(4 \mathrm{f}_{5 / 2}\right)$ and $85.7 \mathrm{eV}\left(4 \mathrm{f}_{7 / 2}\right)$ binding energies were fixed, corresponding to the $\mathrm{Au}(\mathrm{III})$ binding energy (Fig. 3). The SEM images provided further information about the HPG@KCC-1/PPh $2 / \mathrm{Au}$ NPs. SEM images for the fresh HPG@KCC-1/PPh $/$ /Au NPs and the HPG@KCC-1/ $\mathrm{PPh}_{2} / \mathrm{Au}$ NPs after ten reuses are displayed in Fig. 4. After being reused ten times, the dandelion-like structure of the catalyst could still be observed, although the dandelion-like structure collapsed to some extent. The similarity between the structures of the fresh HPG@KCC-1/PPh $/$ /Au NPs and the HPG@KCC-1/ $\mathrm{PPh}_{2} / \mathrm{Au}$ NPs after ten reuses accounts for the high level of recyclability.

In an effort to make the synthesis more applicable, the reusability of the catalyst was also examined for the standard reaction of allylarenes or methyl acrylate with benzoxazole. After completion of the reaction, the mixture was filtered and the catalyst was washed with distilled water and methanol, then dried under reduced pressure. The HPG@KCC-1/PPh $/$ Au NPs were found to be effective for reuse in up to ten consecutive cycles whilst maintaining a high level of activity and selectivity. The catalytic activity was not reduced extremely after ten catalytic cycles, showing that the catalyst is stable and can be regenerated for repeated use (Fig. 5).

In order to study the catalytic activity of various HPG@KCC$1 / \mathrm{PPh}_{2}$ complexes of metal ions, we examined their efficiency for the reaction of allylarenes and benzoxazole (Table 6). Nine separate reactions were examined in the presence of $\mathrm{Au}(\mathrm{III})$, $\mathrm{Cu}(\mathrm{II}), \mathrm{Cr}$ (III), $\mathrm{Cd}$ (II), $\mathrm{Hg}$ (II), $\mathrm{Mn}$ (II), Ni(II), $\mathrm{Zn}$ (II) and $\mathrm{Co}$ (II) complexes. The results indicate that the catalytic efficiency of $\mathrm{Au}(\mathrm{III})$ immobilized onto HPG@KCC-1/PPh 2 was the highest out of all metal ions tested.

\section{Conclusions}

In summary, a novel class of short-fiber KCC-1 mesoporous silica nanoparticles, functionalized with phosphorus ligands, was synthesized for the selective capturing of gold(III), and the nanoparticles exhibited excellent catalytic activity for novel onepot $\mathrm{C}-\mathrm{C}$ coupling reactions for the convenient arylation of 
benzoxazole with good yields. In addition, the catalyst was easily recoverable and reusable. Such a rational design for single-site catalysts with the full utilization of each gold(III) active site, as well as having excellent recyclability and negligible metal leaching, could be favourable for use in green chemistry. Thus, this study of HPG@KCC- $1 / \mathrm{PPh}_{2} / \mathrm{Au}$ nanocatalysts may provide a potential platform for the fabrication of other metal complexes with easy accessibility, which could be used as highly efficient catalysts for various metal complexbased catalytic reactions. This process may be used in the future to develop additional nanocatalysts that possess favorable properties, such as efficiency and ease of reuse.

\section{Conflicts of interest}

There are no conflicts to declare.

\section{Notes and references}

1 M. L. Wang, T. T. Jiang, Y. Lu, H. J. Liu and Y. Chen, J. Mater. Chem. A, 2013, 1, 5923-5933.

2 X. Zhang and Z. Su, Adv. Mater., 2012, 24, 4574-4577.

3 Z. M. de Pedro, E. Diaz, A. F. Mohedano, J. A. Casas and J. J. Rodriguez, Appl. Catal., B, 2011, 103, 128-135.

4 Y. M. Liu, H. Tsunoyama, T. Akita, S. H. Xie and T. Tsukuda, ACS Catal., 2011, 1, 2-6.

5 X. Yang, C. Huang, Z. Y. Fu, H. Y. Song, S. J. Liao, Y. L. Su, L. Du and X. J. Li, Appl. Catal., B, 2013, 140, 419-425.

6 A. S. K. Hashmi, J. P. Weyrauch, M. Rudolph and E. Kurpejovic, Angew. Chem., Int. Ed., 2004, 43, 6545.

7 A. S. K. Hashmi, M. Rudolph, J. P. Weyrauch, M. Wolfle, W. Frey and J. W. Bats, Angew. Chem., Int. Ed., 2005, 44, 2798-2801.

8 N. Debono, M. Iglesias and F. Sanchez, Adv. Synth. Catal., 2007, 349, 2470-2476.

9 A. S. K. Hashmi, M. Rudolph, H. U. Siehl, M. Tanaka, J. W. Bats and W. Frey, Chem.-Eur. J., 2008, 14, 3703-3708.

10 N. D. Shapiro, Y. Shi and F. D. Toste, J. Am. Chem. Soc., 2009, 131, 11654-11655.

11 Y. Zhang, B. Feng and C. Zhu, Org. Biomol. Chem., 2012, 10, 9137-9141.

12 J. A. O’Neill, G. M. Rosair and A.-L. Lee, Catal. Sci. Technol., 2012, 2, 1818-1821.

13 V. K. Y. Lo, Y. G. Liu, M. K. Wong and C. M. Che, Org. Lett., 2006, 8, 1529-1532.

14 V. K. Y. Lo, M. K. Wong and C. M. Che, Org. Lett., 2008, 10, 517-519.
15 M. Z. Wang, M. K. Wong and C. M. Che, Chem.-Eur. J., 2008, 14, 8353-8364.

16 W. Henderson, Adv. Organomet. Chem., 2006, 54, 207-265.

17 V. K. Y. Lo, K. K. Y. Kung, M. K. Wong and C. M. Che, J. Organomet. Chem., 2009, 694, 583-591.

18 K. K. Y. Kung, G. L. Li, L. Zou, H. C. Chong, Y. C. Leung, K. H. Wong, V. K. Y. Lo, C. M. Che and M. K. Wong, Org. Biomol. Chem., 2012, 10, 925-930.

19 K. K. Y. Kung, V. K. Y. Lo, H. M. Ko, G. L. Li, P. Y. Chan, K. C. Leung, Z. Zhou, M. Z. Wang, C. M. Che and M. K. Wong, Adv. Synth. Catal., 2013, 355, 2055.

20 A. S. K. Hashmi, Chem. Rev., 2007, 107, 3180-3211.

21 D. J. Gorin and F. D. Toste, Nature, 2007, 446, 395-403.

22 Z. Li, C. Brouwer and C. He, Chem. Rev., 2008, 108, 32393265 .

23 A. Corma, A. Leyva-Perez and M. J. Sabater, Chem. Rev., 2011, 111, 1657-1712.

24 N. Krause and C. Winter, Chem. Rev., 2011, 111, 1994-2009. 25 L. Zhou, C. Gao and W. Xu, Langmuir, 2010, 26, 11217-11225. 26 Z. Chen, L. Zhou, F. Zhang, C. Yu and Z. Wei, Appl. Surf. Sci., 2012, 258, 5291-5298.

27 Q. Du, W. Zhang, H. Ma, J. Zheng, B. Zhou and Y. Li, Tetrahedron, 2012, 68, 3577-3584.

28 P. Serp and K. Philippot, Nanomaterials in Catalysis, WileyVCH, Weinheim, 2013, p. 496.

29 V. Polshettiwar, Angew. Chem., Int. Ed., 2013, 52, 11199.

$30 \mathrm{~V}$. Polshettiwar and T. Asefa, Nanocatalysis: Synthesis and Applications, 2013.

31 Z. Dong, X. Le, X. Li, W. Zhang, C. Dong and J. Ma, Appl. Catal., B, 2014, 158-159, 129-135.

32 Z. S. Qureshi, P. B. Sarawade, M. Albert, V. D'Elia, M. N. Hedhili, K. Köhler and J. M. Basset, ChemCatChem, 2015, 7, 635-642.

33 V. Polshettiwar, D. Cha, X. Zhang and J. M. Basset, Angew. Chem., Int. Ed., 2010, 49, 9652-9656.

34 N. D. Petkovich and A. Stein, Chem. Soc. Rev., 2013, 42, 37213739.

35 C. M. Parlett, K. Wilson and A. F. Lee, Chem. Soc. Rev., 2013, 42, 3876-3893.

36 C. Liu, X. Li, Z. Gao, X. Wang and Z. Jin, J. Catal., 2015, 71, 3954-3959.

37 G. Durgun, O. Aksın and L. Artok, J. Mol. Catal. A: Chem., 2007, 278, 189-199.

38 S. Paul and J. H. Clark, Green Chem., 2003, 5, 635-638.

39 S. M. Sadeghzadeh, Catal. Sci. Technol., 2016, 6, 1435-1441. 40 S. M. Sadeghzadeh, J. Mater. Chem. A, 2016, 423, 216-223. 